\title{
O ESPAÇO DO “CORPO” NA EDUCAÇÃO DA INFÂNCIA
}

Nara Rejane Cruz de Oliveira

\section{Resumo}

Este trabalho faz uma reflexão sobre o espaço dado ao corpo e ao movimento no contexto da educação infantil. Percebemos que as preocupações com a "educação corporal" na educação infantil não são recentes, porém, na atualidade as propostas não superaram ainda a visão fragmentada de corpo, movimento e criança.

\section{Palavras-Chave}

Corpo; Educação; Infância.

\section{THE SPACE OF THE "BODY" IN THE EDUCATION OF CHILDREN}

Nara Rejane Cruz de Oliveira

\begin{abstract}
This work makes a reflection on the space given to the body and the movement in the context of the childhood education. We perceive that the concerns with the "corporal education" in the childhood education are not recent, however, in the present time the proposals had still not surpassed the fragmented vision of body, movement and child.
\end{abstract}

\section{Key-Words}

Body; Education; Childhood. 


\section{INTRODUÇÃO}

A criança é feita de cem. [...] A criança tem cem linguagens. (...) Mas roubaram-lhe noventa e nove. A escola e a cultura lhe separam a cabeça do corpo. Dizem-lhe: de pensar sem as mãos, de fazer sem a cabeça [...]. Dizem-lhe: que as cem não existem. A criança diz: ao contrário, as cem existem. (MALAGUZZI, 1999).

A preocupação com a educação do "corpo", especialmente no contexto da educação da infância, não é algo recente na sociedade, ao contrário. Desde as primeiras sistematizações pedagógicas, propostas de "educação corporal" têm estado presentes, direta ou indiretamente, em diversas perspectivas, porém, quase sempre associadas a uma visão idealista, dicotomizando corpo e mente. Isso é notável, por exemplo, quando percebemos em Comenius (1997), ainda no século XVII, que os exercícios físicos (movimento) eram pensados na perspectiva de preparar o corpo para glorificar a alma, assim como a utilização do corpo na formação moral e intelectual da criança foi enfatizada em propostas como a de Pestalozzi, no século XIX (SOARES, 1998; MANACORDA, 2000; CAMBI, 1999).

No Brasil, os estudos de Kuhlmann Jr. (1991, 2000) apontam que esta educação do "físico", ainda no século XIX, era utilizada para domar os corpos das crianças pequenas, ou, na perspectiva de Foucault (1979), para docilizá- $\operatorname{los}^{1}$ - cultivando a moral - especialmente daquelas que freqüentavam as instituições de caráter assistencialista, destinadas às crianças de classes populares.

Entretanto, corpo e movimento ainda hoje são considerados elementos contraditórios na Educação Infantil, visto que, por um lado, é freqüente serem postos de forma secundária, todavia, ocupam lugar de destaque nas preocupações de professores. Afinal, é comum ouvirmos professores afirmarem que "as crianças não param quietas no lugar, movimentam-se demais!”. Além disso, há hoje uma preocupação em massa (especialmente em famílias de classe média e alta) com a prática de atividades físicas na infância, resultado, dentre outros fatores, da veiculação pela mídia moderna de inúmeras reportagens sobre a importância dessas práticas para a saúde e bem-estar das crianças, embora muitas vezes sejam disseminados pela mídia mais modismos relacionados ao corpo e movimento infantil, do que necessariamente contribuições. Outro fator indutor da preocupação dos pais em criar oportunidades para seus filhos se movimentarem mais e trabalharem mais seus corpos, vem do fato de que nos grandes centros urbanos, os espaços de brincar estão cada vez mais reduzidos e as brincadeiras de rua de outrora cederam lugar ao medo da violência e ao confinamento doméstico.

\footnotetext{
${ }^{1}$ Foucault afirma que a organização do tempo e espaço em instituições como a escola, por exemplo, produz corpos esquadrinhados, através da submissão às regras de comportamento, punições e recompensas.
} 
Nessa perspectiva, parece-nos que fica relegado às escolas, aos professores e academias, o papel de combater a obesidade infantil, o sedentarismo, dentre outros males que assolam a infância contemporânea. E os espaços para os modismos se exacerbam. Afinal, é comum percebermos em propagandas de escolas infantis (particulares), por exemplo, a oferta de modalidades como ballet, lutas, dentre outros, como vantagens da escola. Além de muitas academias, nas quais proliferam turmas intituladas "baby class" de várias modalidades. Entretanto, quase sempre tais ofertas (especialmente em escolas infantis) nem chegam perto da qualidade almejada. É comum percebermos professores despreparados, muitas vezes utilizando-se de métodos não adequados, ultrapassados, em "movimentos geométricos reivindicando apenas partes isoladas do corpo" (DIECKERT, 1985), tolhendo assim o movimento criativo, a espontaneidade da criança, a criança em sua totalidade.

No contexto das instituições de educação infantil públicas, percebemos também que existe uma preocupação com o corpo e movimento das crianças, nem sempre relacionada a modismos. Porém, grande parte dos professores de creches e pré-escolas não se sente preparada para promover atividades corporais com as crianças, tanto pela ausência desse tema em sua formação, quanto pelas próprias condições objetivas de trabalho e, muitas vezes de estrutura da instituição, como afirmam algumas professoras $^{2}$. Dessa forma, muitas vezes resta às crianças apenas um escasso tempo para brincar no parquinho ou outros espaços na hora do "recreio", ou ainda o recreacionismo com fím em si mesmo ministrado pelas professoras.

Portanto, essas considerações nos permitem afirmar que, mesmo no século XXI, a Educação Infantil não superou ainda a visão fragmentada de corpo, movimento e criança, apesar de percebermos a afirmação da importância do corpo e do desenvolvimento da motricidade da criança, especialmente em produções científicas e acadêmicas (WALLON, 1973; GALVÃO, 1992; OLIVEIRA, 2002; SAYÃO, 2002a; dentre outros). Como afirma Tonucci (1997), a criança tem um corpo e uma história, mas na escola, parece que este corpo não serve para nada. Ou ainda, nas palavras de Malaguzzi (1999) a criança tem muitas linguagens, mas a escola e a cultura teimam em lhe separar a cabeça do corpo.

Ou seja, para Sayão (2002b), parece que o adulto se "esquece" gradativamente de como, quando era criança, o sistema de comunicação estabelecido com o meio social integrava o movimento como

\footnotetext{
${ }^{2}$ Essas afirmações foram feitas por várias professoras (termo utilizado no feminino, considerando que grande parte do corpo docente de instituições infantis é de mulheres) com as quais tivemos a oportunidade de trabalhar nos últimos três anos, tanto em cursos de capacitação, quanto em observações realizadas em instituições de educação infantil.
} 
expressão. Com este "esquecimento", o adulto muitas vezes cobra da criança uma postura de seriedade, linearidade e imobilidade, inibindo pouco a pouco a espontaneidade, a criatividade, a ousadia, o direito de se movimentar, presentes em seus gestos e movimentos corporais.

\section{CORPO E MOVIMENTO NA EDUCAÇÃO DA INFÂNCIA}

Foi por volta do século XVI que apareceu o que Áries (1981) intitulou de "sentimento de infância". Segundo Kramer (1995) este sentimento de infância não está relacionado com afeição pelas crianças; corresponde à tomada de consciência, por parte do adulto, do potencial de desenvolvimento destas e da particularidade infantil. Conforme Faria (1999), a partir desse período a infância ganhou o status de categoria peculiar do social, em que a criança passou a ser vista como uma figura da coletividade, dotada de necessidades próprias, merecedora de atenção e intervenções educativas condizentes, ao menos nas classes mais abastadas. De acordo com Kramer (1995), a criança neste contexto passou a ser vista como um ser imperfeito e incompleto, necessitando, pois, ser moralizada através da educação feita pelo adulto.

Nesse contexto, a partir do século XVII a educação da infância passou a se constituir como preocupação. O destaque pedagógico neste século foi Comenius (1997), que apontou, dentre outras coisas, a criação de uma escola maternal e primária e seus respectivos princípios educativos. Em suas propostas educativas para a infância, enfatizou a importância dos exercícios físicos na formação da criança, ainda que numa perspectiva idealista (o trabalho do corpo em função da glorificação da alma).

O século XVIII inaugura um novo momento na educação, fruto da laicização e emancipação política, social e cultural (CAMBI, 1999). Neste contexto, o francês Rousseau deu suporte aos novos ideais educacionais e centralizou o tema da infância na educação. Segundo Manacorda (2000), a perspectiva da “educação natural” de Rousseau, apesar de elitista e idealista, revolucionou de certa forma a pedagogia, privilegiando uma educação centrada no sujeito, com destaque para a educação dos sentidos, a valorização do jogo, do trabalho manual, da higiene, do exercício físico e experiência direta com as coisas. Rousseau considerava que esses elementos eram potenciais na construção do conhecimento e intelectualidade infantil.

Manacorda (2000) destaca também que, uma das experiências concretas ocorridas entre os anos de mil e setecentos e mil e oitocentos advém de Pestalozzi, na Suíça, que de forma declarada seguiu a trilha de Rousseau. As idéias pedagógicas de Pestalozzi tiveram significativo impacto na educação escolar e na educação de crianças do período pré-escolar. A ambição de Pestalozzi foi a de juntar o homem natural e a 
realidade histórica; no entanto, o fez no contexto e limites de seu tempo. Nessa concepção educacional surgiu uma série de disciplinas e atividades até então desconhecidas pela educação popular tradicional; dentre elas a ginástica que, para Pestalozzi, tinha grande utilidade para o corpo, no sentido da formação da moral e nobreza. Em sua perspectiva, através do ato ginástico poderiam ser desenvolvidos na criança a força, a resistência, a coragem, a persistência e o vigor. Neste sentido, todos os exercícios deveriam ser classificados não somente segundo as disponibilidades motoras do indivíduo, mas respeitando as regras da natureza, primando pelos movimentos livres, espontâneos, racionais e, sobretudo, naturais. Assim, a ginástica, sob o aspecto intelectual, promoveria na criança a faculdade de controlar com adestramento e reflexão as suas ações; sob o aspecto estético, conferiria presteza física e boa postura; sob o aspecto moral, asseguraria o domínio da vontade sobre o corpo, o que permitiria à criança seguir os preceitos éticos e sociais do dever (GRIFFI, 1989).

No século XIX, Froebel, influenciado pelas idéias de Rousseau e, sobretudo, de Pestalozzi, de quem foi discípulo, idealizou um tipo de instituição de educação infantil diferente dos abrigos de infância da época: o jardim de infância (kindergarten). Fundado na Alemanha e posteriormente difundido em outros países, os jardins de infância eram locais aparelhados, preparados para o desenvolvimento da criança. O desenvolvimento infantil, conforme Froebel, dependia de uma atividade espontânea (o jogo), de uma atividade construtiva (o trabalho manual) e do estudo da natureza. Valorizando a expressão corporal, o gesto, o desenho, o brinquedo, o canto, a linguagem e os interesses naturais da criança, Froebel concebia a linguagem como primeira forma de expressão social e o brinquedo como forma de auto-expressão, pois a auto-atividade, para ele, representava a base e o método de toda instrução. Segundo Griffi (1989), Froebel colocou no jardim-de-infância alemão, em primeiro lugar, o jogo e uma vasta série de exercícios ginásticos, acompanhados também por música e canto. Para este autor, a educação infantil de Froebel ficava sempre concentrada sobre uma atividade de movimento e de jogo disciplinados, entendidos como atividades espontâneas da criança.

Nas primeiras décadas do século XX, percebemos preocupações significativas com a educação física nas propostas educativas. No contexto brasileiro, na década de 1930, com a criação, por Mário de Andrade, dos Parques Infantis em São Paulo, as atividades das crianças eram organizadas na perspectiva de liberdade de movimentos. Mário de Andrade acreditava que o corpo da criança deveria ser livre. Entretanto, sendo obrigado a sair do Departamento de Cultura do município de São Paulo, Nicanor Miranda assumiu o cargo e as atividades passaram a ter a finalidade de contribuir para a formação 
higiênica das crianças de três a doze anos de idade da classe trabalhadora, sendo os exercícios físicos enfatizados na perspectiva da recreação.

A partir da década de 1970, a psicomotricidade adentrou o cenário pedagógico brasileiro e percebemos que, desde então, o discurso da educação infantil, especificamente quanto à questão do corpo e movimento das crianças, buscou nela o seu respaldo, na perspectiva da "formação integral". Este fato não deixou de conferir uma perspectiva propedêutica quanto à movimentação das crianças. Neste contexto, segundo Sayão (2002b), parece haver um descompasso entre os desejos das crianças e a intencionalidade dos professores, pois estes parecem sempre notar o que "falta" às crianças e não o que as mesmas conquistam. Ou seja, as crianças são percebidas pelos professores por aquilo que não conseguem fazer e em função disso, a pedagogia se ocupa de elaborar um arsenal de jogos pedagógicos, exercícios e testes, utilizados como antídotos para acelerar as aprendizagens e suprir os déficits.

Ao mesmo tempo, a área de educação física também buscava na psicomotricidade o respaldo para sua finalidade pedagógica, em oposição aos métodos tradicionais, fundamentados no esportivismo e na aptidão física. Em estudo sobre as principais influências teóricas da educação física na pré-escola na década de 1990, Sayão (1997) aponta que as mesmas estariam respaldadas na recreação (como compensação das energias gastas em sala de aula ou outras atividades), na psicomotricidade (como instrumental e preparação para atividades futuras - por exemplo, a alfabetização) e no desenvolvimento motor (treino de habilidades motoras). Entretanto, tais influências não se manifestariam isoladas, na medida em que várias das abordagens se utilizavam destes discursos articulados. Para esta autora, o funcionamento da educação física nessas perspectivas tende a uma visão fragmentária, gerando a dicotomia corpo-mente; a dicotomia sala-pátio; a dicotomia teoria-prática. A nosso ver, ainda hoje, uma década depois, estas mesmas influências continuam se manifestando.

No contexto da educação infantil, nos últimos anos, especificamente a partir da década de 1980, as pesquisas deram alguns saltos qualitativos, especialmente no que diz respeito à variedade de temáticas abordadas, segundo Rocha (1999). Apesar desta variedade, percebemos que as investigações que abordam a questão da educação do corpo e o movimento em creches e pré-escolas, assim como a educação da criança em sua totalidade, ainda precisam ser mais incisivas. 
Mesmo com o avanço no que diz respeito à qualidade na produção acadêmica na Educação Infantil, percebemos que as questões relativas ao corpo, movimento e desenvolvimento infantil ainda são em grande parte contraditórias, a exemplo do Referencial Curricular Nacional para a Educação Infantil RCNEI (BRASIL, 1998), constituinte das políticas do governo federal para a educação infantil. Nele, é perceptível uma visão de fragmentação do conhecimento e conseqüentemente do corpo, apesar do discurso da totalidade do ser humano. Cerisara (2000), ao analisar alguns aspectos formais e estruturantes do RCNEI, aponta algumas incoerências, por exemplo:

- $\quad$ A inclusão no documento do brincar e movimento poderiam significar um avanço, se não tivessem recebido o tratamento escolar, sendo reduzidos a conteúdos a serem ensinados e itens de avaliação. Nesse sentido corre-se o risco de serem tolhidos preciosos momentos da criatividade infantil ao se pensar o movimento numa perspectiva propedêutica.

- Separar o brincar do movimento e do conhecimento de si e do outro é impróprio. Assim como definir conteúdos para estas áreas reforça a idéia de objeto de ensino e enquadramento normativo.

- No tratamento dado ao brinquedo, o texto critica como tem sido trabalhada a brincadeira e o movimento, mas incorre no mesmo erro. Ou seja, a atividade pela atividade, o brincar pelo brincar continua imperando, sem um corpo teórico sustentável.

Percebemos que o corpo e o movimento ainda são questões difíceis de lidar no contexto da educação infantil. Não tanto pela ausência de estudos sobre o tema, mas talvez pela distância entre as teorias que são propostas e as práticas no cotidiano das instituições, além de uma formação profissional que consiga abordar o tema com maior profundidade. Então, o que fazer? Como pensar concretamente uma perspectiva de educação infantil que respeite os direitos da criança a uma educação para a totalidade, integrando suas múltiplas linguagens expressivas?

\section{EXERCÍCIO FÍSICO OU MOVIMENTO COMO LINGUAGEM: QUAL O PAPEL DA “EDUCAÇÃO CORPORAL” NA INFÂNCIA?}

Pensar o corpo e o movimento contexto da educação infantil nos convida a refletir sobre sua importância no desenvolvimento da criança. 
A humanidade se constitui na e através da linguagem. A linguagem pode ser definida como a forma de comunicação e expressão entre as pessoas, por meio de diferentes símbolos (a escrita, o gesto, a fala, o desenho, o movimento...), o que faz com que ocorra a aprendizagem e o desenvolvimento. A incompreensão das múltiplas formas da criança se comunicar com o mundo têm gerado, historicamente, uma série de equívocos educacionais, acarretando graves conseqüências à formação humana.

Pensar o ser humano em sua totalidade requer a compreensão de que as várias dimensões humanas são indissociáveis, ou seja, não se separam e condicionam-se mutuamente. No caso das questões relativas ao corpo e movimento da criança, é imprescindível a compreensão de que não possuímos um corpo e uma mente separados, mas sim, um corpo que sente, pensa e age de forma indissociável, por meio de múltiplas linguagens. Não existe pensamento separado da ação, pois toda ação humana pressupõe um pensamento, com objetivos definidos por necessidades constituídas cultural e historicamente (VIGOTSKY, 1998). Frente a estas questões, necessário se faz considerarmos o movimento na educação infantil como linguagem expressiva, e, neste contexto, como elemento imprescindível à formação da criança em sua totalidade.

A criança tem uma maneira expressiva, gestual, simbólica e lúdica de estar no mundo, tendo o direito de viver plenamente a infância, conforme Dias (1997). Segundo Oliveira (2002), as diferentes linguagens possibilitam à criança troca de informações, observações, planos e idéias, estabelecendo novos recursos de aprendizagem, integrando-se às funções psicológicas superiores e as transformando.

Pensar a criança em sua totalidade, com suas múltiplas linguagens, requer colocar no mesmo plano os aspectos sociais, cognitivos, afetivos e motores (WALLON, 1973). Conforme Wallon (1973), o movimento é imprescindível no processo de desenvolvimento infantil, pois não influencia apenas no desenvolvimento psíquico da criança e nas suas relações com os outros, mas também no comportamento habitual, na afetividade, além de estar relacionado à função postural.

Para Filgueiras (2002), o movimento é uma das formas que a criança tem de explorar o mundo ao seu redor e interagir. Por meio dessa exploração e interação, a criança pode construir conhecimentos sobre seus limites e possibilidades, conhecer e dominar o uso de diferentes objetos/instrumentos que a humanidade desenvolveu, assim como iniciar a compreensão de quais relações pode estabelecer com eles. O movimento também é parte integrante da construção da autonomia e identidade da criança. 
Segundo Oliveira (2002), a motricidade também é desenvolvida por meio da manipulação de objetos de diferentes formas, cores, volumes, pesos e texturas. Quando a criança altera sua colocação postural lidando com esses objetos e variando as superfícies de contato com eles, diversos segmentos corporais

com contrações musculares de diferentes intensidades são trabalhados, fazendo com que nesse esforço, ela se desenvolva.

Assim, pode-se dizer que a função postural está ligada também à atividade intelectual, numa relação de reciprocidade (GALVÃO, 1995). Segundo Filgueiras (2002), para a criança, essa relação de reciprocidade é relevante, na medida em que ela aprende por meio da expressão corporal e também experimentando desafios motores.

Desse modo, a linguagem corporal, expressa na motricidade da criança, não deve ser deixada à margem, como se as aprendizagens significativas estivessem apenas vinculadas à linguagem escrita. Aliás, sobre esta questão, Gonçalves (2000) afirma que pensar a educação da criança somente na perspectiva da leitura e escrita é partir de idéias reducionistas. Isto porque o nosso desenvolvimento pleno vai muito além do ato de ler e escrever. $\mathrm{O}$ autor, retomando o caminho evolutivo que a humanidade percorreu (filogênese - desenvolvimento da espécie e ontogênese - desenvolvimento do indivíduo), aponta que o ser humano aprende primeiro a se movimentar, situar-se no ambiente e explorá-lo, só bem mais tarde a escrever. E, considerando que a escrita não ultrapassa os 3.200 anos de existência, portanto, recente no processo evolutivo do ser humano, é um erro a educação desconsiderar o movimento ou tratá-lo de forma equivocada.

As leis educacionais brasileiras apontam para a garantia de oferecimento de uma educação infantil de qualidade, respeitando as características de desenvolvimento da criança e primando pelo seu desenvolvimento pleno. Assim, considerando o movimento como uma das múltiplas e importantes linguagens expressivas, a criança tem o direito de não ser privada do mesmo na educação infantil ou ser exposta a práticas espontaneístas.

Nesse sentido, não basta apenas abordar o movimento na educação infantil, mas pensar concretamente em uma prática pedagógica que o estimule de forma criativa e não reprodutiva. Ou, segundo Dieckert (1985) instigar a criança a descobrir, desenvolver, experimentar com, interpretar, expressar, criar com, cooperar, organizar-se com, satisfazer-se com e melhorar o corpo, o movimento, o jogo. Dessa forma, o movimento 
deve ser entendido como algo mais que simples deslocamento do corpo no espaço; precisa ser entendido como uma linguagem expressiva, cheia de intencionalidade, constitutiva da cultura corporal humana (BRASIL, 1998).

\title{
CONSIDERAÇÕES FINAIS
}

\author{
A educação, qualquer que seja o nível em que se dê, se fará tão mais verdadeira quanto mais \\ estimule o desenvolvimento desta necessidade radical dos seres humanos, a de sua \\ expressividade. (MOREIRA, 2002).
}

Segundo Moreira (2002), a maioria das crianças, à medida que vai crescendo se esquece de como criar histórias, endurece o corpo e não canta mais. Isso nos mostra que as múltiplas linguagens expressivas continuam negligenciadas na educação da infância. A contenção do movimento, da expressividade, são práticas ainda comuns no cotidiano das instituições, apesar das pesquisas e produções acadêmicas enfatizarem o contrário. Isto nos mostra a fragilidade da formação profissional, a falta de conhecimento dos professores sobre "o que fazer" na educação infantil, bem como a ausência de maiores investimentos neste setor, especialmente no contexto de instituições públicas, apesar da existência de algumas experiências pedagógicas inovadoras, relatadas em congressos e produções da área. O que nos mostra que é possível reverter esse quadro e investir em uma educação infantil de qualidade.

Desenvolver múltiplas linguagens, por vezes tão negligenciadas (como o desenho e o movimento, por exemplo), é tarefa do educador. Dar voz à expressividade da infância é dar voz às "cem linguagens da criança" (MALAGUZZI, 1999), às suas expressões lúdicas, à formação de um ser humano aberto às formações e transformações.

\section{REFERÊNCIAS}

ARIÈS, P. História social da criança e da família. Rio de Janeiro: Guanabara, 1981.

BRASIL. Ministério da Educação e do Desporto. Secretaria de Educação Fundamental. Referencial Curricular Nacional para a educação infantil. Brasília: MEC/SEF, 1998. 3v.

CAMBI, Franco. História da pedagogia. São Paulo: Ed. da Unesp, 1999.

CERISARA, A. B. Produção acadêmica na área de educação infantil a partir da análise de pareceres sobre o referencial curricular nacional da educação infantil: primeiras aproximações. In: FARIA, A. L. 
G. de; PALHARES, M. S. (Org.). Educação infantil pós-LDB: rumos e desafios. 2. ed. Campinas: Autores Associados, 2000. p.19-49.

COMENIUS. Didática magna. São Paulo: Martins Fontes, 1997.

DIAS, M. C. M. Saberes essenciais ao educador da primeira infância: uma reflexão na perspectiva dos protagonistas. 1997. 192 f. Tese (Doutorado) - Faculdade de Educação, Universidade de São Paulo, São Paulo, 1997.

DIECKERT, J. Prefácio: Criatividade e educação física no Brasil. In: TAFFAREL, C. N. Z. Criatividade nas aulas de Educação Física. Rio de Janeiro: Ao Livro Técnico, 1985.

FARIA, A. L. G. de. Educação pré-escolar e cultura. Campinas: Ed. da Unicamp, 1999.

FILGUEIRAS, I. P. A criança e o movimento: questões para pensar a prática pedagógica na educação infantil e no ensino fundamental. Revista do Instituto Avisa Lá, São Paulo, n.11, p.11-19, jul. 2002.

FOUCAULT, M. Vigiar e punir: história da violência nas prisões. Petrópolis: Vozes, 1979.

GADOTTI, M. História das idéias pedagógicas. São Paulo: Ática, 1999.

GALVÃO, I. O espaço do movimento: investigação no cotidiano de uma pré-escola à luz da teoria de Henri Wallon. 1992. 113f. Dissertação (Mestrado)- Faculdade de Educação, Universidade de São Paulo, São Paulo, 1992.

GALVÃO, I. Henri Wallon: uma concepção dialética do desenvolvimento infantil. Petrópolis: Vozes, 1995.

GONÇALVES, C. J. Educação Física: ler e escrever também com o corpo em movimento. In: NEVES, I. C. B. et al (Org.). Ler e escrever: compromisso de todas as áreas. Porto Alegre: Ed. da UFRGS, 2000. p.45-62.

GRIFFI, G. História da Educação Física e do esporte. Porto Alegre: Luzzatto, 1989.

KRAMER, S. A política do pré-escolar no Brasil: a arte do disfarce. 5. ed. São Paulo: Cortez, 1995.

KUHLMANN JÚNIOR, M. Instituições pré-escolares assistencialistas no Brasil (1889-1922). Cadernos de Pesquisa, São Paulo, n.78, p.17-26, ago. 1991.

. Educando a infância brasileira. In: LOPES, E. M. T.; FARIA FILHO, L; V.; GREIVE, C. (Org.). 500 anos de educação no Brasil. Belo Horizonte: Autêntica, 2000. p. 469-496.

MALAGUZZI, L. Ao contrário, as cem existem. In: EDWARDS, C.; GANDINI, L.; FORMAN, G. As cem linguagens da criança: a abordagem de Reggio Emilia na educação da primeira infância. Porto Alegre: Artmed, 1999. p.V.

MANACORDA, M. A. A História da educação: da antiguidade aos nossos dias. 8.ed. São Paulo: Cortez, 2000. 
MOREIRA, A. A. A. O espaço do desenho: a educação do educador. 9. ed. São Paulo: Loyola, 2002.

OLIVEIRA, Z. de M. R. de. Educação infantil: fundamentos e métodos. São Paulo: Cortez, 2002.

ROCHA, E. C. A pesquisa em educação infantil no Brasil: trajetória recente e perspectivas de consolidação de uma pedagogia. Florianópolis: Núcleo de Publicações da UFSC, 1999.

SAYÃO, D. T. Educação Física na pré-escola: principais influências teóricas. In: CONGRESSO BRASILEIRO DE CIÊNCIAS DO ESPORTE, 10., 1997, Goiânia. Anais... Goiânia; CBCE, 1997. p.594601.

- Corpo e movimento: notas para problematizar algumas questões relacionadas à educação infantil e educação física. Revista Brasileira de Ciências do Esporte, Campinas, v. 23, n. 2, p.55-67, jan. 2002a.

. Corpo e movimento: alguns desafios pra a educação infantil. Revista eletrônica zero a seis, n. 5 , jan./jul. 2002b. Disponível em: www.ced.ufsc.br/zeroaseis. Acesso em: 09 maio. 2007.

SOARES, Carmen. Imagens da educação do corpo: estudos a partir da ginástica francesa no século XIX. Campinas: Papirus, 1998.

TONUCCI, F. Com olhos de criança. Porto Alegre: Artes Médicas, 1997.

VIGOTSKY, L. S. A formação social da mente. 6. ed. São Paulo: Martins Fontes, 1998.

WALLON, H. Psicologia e educação da infância. Lisboa: Stampa,1973. 


\section{Nara Rejane Cruz de Oliveira}

Universidade de São Paulo

\section{Referência do artigo:}

\section{ABNT}

OLIVEIRA, N. R. C. O espaço do "corpo" na educação da infância. Conexões, v. 6, n. 1, p. 1-13, 2008.

\section{APA}

Oliveira, N. R. C. (2008). O espaço do “corpo” na educação da infância. Conexões, 6(1), 1-13.

\section{VANCOUVER}

Oliveira NRC. O espaço do “corpo" na educação da infância. Conexões, 2008, 6(1): 1-13. 